\title{
ESTRATÉGIAS DE INTERNACIONALIZAÇÃO DE EMPRESAS MULTINACIONAIS BRASILEIRAS E AVALIAÇÃO DAS DIMENSÕES CULTURAIS NACIONAIS: ESTUDO DE CASO SETOR DE FABRICAÇÃO DE IMPLEMENTOS AGRÍCOLAS.
}

\section{RESUMO}

Este artigo tem por objetivo esboçar um quadro evolutivo das multinacionais brasileiras, a partir da perspectiva do desenvolvimento das multinacionais latino-americanas, sob o ponto de vista de sua inserção no processo de globalização. Busca-se caracterizar o perfil típico destas empresas de acordo com o Modelo de Dunning para se confirmar se esta tipologia ainda se adéqua a caracterização das estratégias de internacionalização. De forma complementar, utiliza-se a Teoria das Dimensões Culturais de Hofstede como meio de descrever a influência dos fatores culturais no processo decisório das empresas e disposição à internacionalização e multinacionalização. Ao fazer isto, verificou-se em que medida o alinhamento estratégico está orientado a metas em termos de: (i) exploração de recursos naturais e vantagens de custos de mão de obra não qualificada (resource seeking); (ii) vantagens de localização e sinergias de mercado (market seeking); (iii) investimentos orientados à busca de ativos estratégicos do tipo efficiency seeking (aquelas que buscam racionalizar a produção e explorar economias de especialização e localização); (iv) investimentos do tipo strategic asset seeking (voltados à aquisição de recursos e competências com o objetivo de incrementar sua competitividade por meio de da inovação e crescimento das capacidades estratégicas). Pretende-se também sumarizar o quadro referencial que possibilite o desenvolvimento de uma agenda futura de pesquisas para o delineamento das principais estratégias, das políticas públicas dos Estados Nacionais e também as estratégias financeiras destas empresas.

Palavras-chaves: Multinacionais Brasileiras; Investimento Direto Estrangeiro; Globalização; Multinacionais LatinoAmericanas e Multinacionais de Países Emergentes.

\section{STRATEGIES OF INTERNATIONALIZATION OF MULTINATIONAL BRAZILIAN ENTERPRISES: EVALUATION OF THE CULTURAL NATIONAL DIMENSIONS.}

\begin{abstract}
This article has since objective sketches an evolutive picture of the Brazilian multinationals, from the perspective of the development of the Latin-American multinationals, from the point of view of his insertion in the process of globalization. It is looked to characterize the typical profile of these enterprises in agreement with the Model of Dunning to be confirmed if this typology still if adequate the characterization of the strategies of internationalization. In the complementary form, there is used the Theory of the Cultural Dimensions of Hofstede .While doing this, one checked in which measure the strategic alignment is orientated á marks in terms of: (i) exploration of natural resources and advantages of costs of labour not qualified (resource seeking); advantages (ii) of location and synergies of market (market seeking); investments (iii) orientated to the search of strategic assets of the type efficiency seeking (for what they look to rationalize the production and to explore savings of specialization and location); investments (iv) of the type strategic asset seeking (turned to the acquisition of resources and competences with the objective to develop his competitiveness through of the innovation and growth of the strategic capacities). There is claimed also summarize the picture referential system that makes possible the development of a future diary of inquiries for the delineation of the principal strategies, of the public politics of the National States and the financial strategies of these enterprises.
\end{abstract}

Keywords: Brazilian Multinationals; Funding Direct Investment; Globalization; Brazilian Multinationals. 
Estratégias de Internacionalização de Empresas Multinacionais Brasileiras e Avaliação das Dimensões Culturais Nacionais: Estudo de Caso Setor de Fabricação de Implementos Agrícolas.

\section{ESTRATEGIAS DE INTERNACIONALIZACIÓN DE LAS EMPRESAS MULTINACIONALES Y \\ EVALUACIÓN DE BRASILEÑOS NACIONAL DE CULTURA DIMENSIONES: ESTUDIO DE CASO DE MANUFACTURA SECTOR DE IMPLEMENTOS AGRÍCOLAS.}

\section{RESUMEN}

En este artículo se pretende esbozar un marco evolutivo de las multinacionales brasileñas, desde la perspectiva del desarrollo de las multinacionales de América Latina, desde el punto de vista de su integración en el proceso de globalización. Buscamos para caracterizar el perfil típico de estas empresas según el modelo de reclamación para confirmar que esta tipología todavía se ajusta a la caracterización de las estrategias de internacionalización. Como complemento, se utiliza la Teoría de las dimensiones culturales de Hofstede como medio de describir la influencia de los factores culturales en el proceso de toma de decisiones de las empresas y la voluntad de internacionalización y transnacionalización. Al hacer esto, se encontró que a medida que la alineación estratégica se orienta metas en términos de: (i) la explotación de los recursos naturales y ventajas de costo de mano de obra no calificada (recurso que busca); (ii) las ventajas de ubicación y las sinergias del mercado (market seeking); (Iii) orientado a la búsqueda de activos estratégicos de la búsqueda de la eficiencia (los que tratan de racionalizar la producción y aprovechar las economías de especialización y ubicación) las inversiones; (iv) Las inversiones en la búsqueda de activos estratégicos tipo (centrado en la adquisición de recursos y conocimientos con el fin de aumentar su competitividad mediante la innovación y las capacidades estratégicas de crecimiento). También tenemos la intención de resumir el marco tecnológico que permite el desarrollo de una agenda de investigación futura para el diseño de las principales estrategias, las políticas públicas de los estados nacionales y también las estrategias financieras de estas empresas.

Palabras-clave: Las Multinacionales Brasileñas; La Inversión Extranjera Directa; Globalización; Multinacional Multinacionales de América Latina y Los Países Emergentes.

\footnotetext{
${ }^{1}$ Doutor em Engenharia de Produção pela Universidade de São Paulo - USP. Professor do Programa de Mestrado Profissional em Admnistração - Gestão de Projetos da Universidade Nove de Julho - PMPA-GP/UNINOVE. Brasil. E-mail: ricardolr@uninove.br

${ }^{2}$ Doutor em Engenharia de Produção, Escola Politécnica da Universidade de São Paulo - POLI/USP. Professor do Departamento de Administração da Faculdade de Economia, Administração e Contabilidade da Universidade de São Paulo - FEA/USP. Brasil. E-mail: plonski.usp@gmail.com
} 


\section{INTRODUÇÃO}

A investigação quanto ao caráter e natureza dos Investimentos Diretos Estrangeiros (IDE) nos países emergentes ou em desenvolvimento (PED) possui natureza dual. $\mathrm{O}$ fenômeno é dirigido dos países centrais (PC) para os PED e PC. Já os PED também realizam investimentos tanto para os $\mathrm{PED}$, como para os próprios PC. O fenômeno é relevante uma vez que muitas das empresas multinacionais dos países emergentes (EMPED) atuam como fornecedores de outras empresas provenientes dos PC. Em 1997, os PED receberam 37\% dos IDE e foram responsáveis pela realização de apenas $14 \%$. Destes, apenas $9 \%$ provieram de EMPED Latino-americanas (Chudnovsky, 2004). A origem dos IDE das EMPED é predominantemente asiática, mais precisamente advém do sul e sudeste asiáticos, com predominância da Coréia do Sul, Cingapura e Taiwan. Estes IDEs corresponderam a $88 \%$ do total dos PED (Chudnovsky, 2004). Coincidentemente, tais países são ao mesmo tempo os maiores receptores de IDE, e têm alcançado altos índices de crescimento econômico, industrial e comercial (Lall, 1997).

Estatísticas publicadas pela UNTAD (Conferência das Nações Unidas para o Comércio e Desenvolvimento) explicitam que das 50 maiores EMPED, $30(60 \%)$ são de origem asiática e apenas $30 \%$ são de origem Latino-americana (Chudnovsky, 2004). Outro fato importante é o perfil em termos de atividades destas empresas; (i) as de origem asiática possuem o perfil predominantemente intensivo em recursos estratégicos ou alta tecnologia (eletroeletrônicos, automotivos, equipamentos elétricos, química pesada e fina); (ii) as de origem Latino-americana atuam fortemente nos segmentos vinculados à exploração de petróleo, indústria de alimentos e bebidas e atividades vinculadas à indústria de extração mineral (cimento e mineração). Ghemawat (2002) estabelece as principais relações teóricas entre o Modelo de Dunning e a Teoria das Dimensões de Hofstede, revista por Minkov e Hofstede (2012). Ao fazer isto, conclui que as empresas de origem nos países onde a distância do poder é predominante possuem um maior número de empresas classificadas dentro da estratégia asset seeking.

Dado este fenômeno, o estudo sistêmico do quadro referencial teórico que envolve a perspectiva evolutiva das EMPED constitui contribuição teórica importante em termos de preenchimento da enorme lacuna existente na caracterização de uma tipologia das EMPED Latino-americanas, sobretudo as de origem brasileiras.

Ante ao exposto, este estudo tem como objetivos identificar o padrão (teórico) do processo de multinacionalização das EMNS brasileiras. Ao fazer isto busca caracterizar o estágio que a maior parte das
EMNS brasileiras por meio de subsidiárias no exterior efetivamente se encontra. Dois referenciais teóricos são adotados: (i) tipologia de Dunning, particularmente a teoria das vantagens locacionais específicas, associada à hipótese do ciclo de vida do produto (HCVP); (ii) escola nórdica, particularmente Hörnell, et. al, (1973), Johanson e Wiedersheim-Paul (1974) e Johanson e Vahlne (2003, 1990, 1977). A integração entre estás é feita à luz da Teoria das Dimensões Culturais de Hofstede, tal como revista por Ghemawat e Reiche (2011) e também por Minkov e Hofstede (2012). Com esta última pretende levantar aspectos comportamentais e a influência destes no processo decisório e padrão de inversões. A próxima seção fixa a abordagem metodológica empregada.

\section{METODOLOGIA}

Este estudo possui viés exploratório-descritivo que, segundo Cooper e Schindler (2008), deve ser aplicado quando o foco da investigação se relaciona a questões já cristalizadas (no caso do presente estudo: entendimento do fenômeno da internacionalização de empresas) e de natureza ex post fato (onde o pesquisador não tem meios de controlar variáveis, como meio de intervir e ou avaliar a influência de variáveis explanatórias sobre fenômeno(s) ou variáveis de interesse), Mais especificamente, o método exploratório deve ser empregado em situações onde o pesquisador não possui clara ideia dos problemas que irá enfrentar. Neste caso, recomenda-se que o pesquisador se oriente no sentido de desenvolver conceitos de forma mais clara, estabelecer prioridades, desenvolver definições operacionais associadas aos fenômenos sob investigação. Adicionalmente, a combinação da abordagem exploratória com técnicas de caráter descritivo conduz a um melhor entendimento de fenômenos ou características relacionadas à uma "população alvo", permitindo a identificação e ou avaliação das possíveis associações entre variáveis que possam (ou não) ser importantes para a apreensão de um dado fenômeno.

De fato, o emprego do método se justifica, pois objetivos estão associados à identificação de padrão (teórico-explicativo) associado ao processo de multinacionalização das EMNS brasileiras. Busca-se caracterizar o estágio que a maior parte das EMNS brasileiras que atuam no exterior efetivamente se encontra a partir da (i) tipologia do Modelo de Dunning, (ii) teoria das vantagens locacionais específicas, (iii) hipótese do ciclo de vida do produto, bem como do (iv) Modelo da Escola Nórdica e ainda da (v) Teoria das Dimensões Culturais de Hofstede. Por meio da avaliação de estudo de caso e à luz desta última pretende-se melhor apreender os aspectos comportamentais e influencia desta dimensão no 
processo decisório destas empresas, inclusive na tomada de decisão com relação às estratégias de internacionalização.

O emprego do método exploratório-descritivo foi feito por meio de estudo de caso único. Segundo Eisenhardt e Graebner (2007), Eisenhardt (1989) e Yin (2000), ao ser empregado como meio de dar conta de perguntas do tipo "como" e "por que", o estudo de caso possui viés explanatório, pois não demanda controle do pesquisador sobre variáveis e focaliza eventos contemporâneos. Particularmente, um estudo de caso único se aplica nas seguintes situações: (i) teste de teoria consolidada (caso decisivo); (ii) avaliação de situação rara ou extrema (muito empregada no campo da medicina); (iii) em situações onde se apresente fenômeno típico ou representativo (destinado a apreender eventos comuns do dia-a-dia); (iv) em geral, aplicado na ocorrência de eventos raros, onde surge a oportunidade de apreende-los; (v) estudos de corte longitudinais (onde são implantados estudos de caso único sobre mesmo objeto em dois pontos distintos no tempo).

A despeito destas situações, o estudo de caso único pode ser empregado em outras situações. Sob o prisma da presente pesquisa, este será empregado como caso-piloto (Yin, 2000). Nesta situação este se aplica quando constitui "o primeiro de um estudo de casos múltiplos" (Yin, 2000 p. 64). Trata-se do que Yin (2000) denomina de caso ilustrativo, onde "o estudo de caso único não pode ser encarado como um estudo completo em si mesmo" (Yin, 2000 p. 64); compreende, igualmente, um primeiro approach ou insight na consolidação de abordagem explicativa-descritiva para avaliação do fenômeno da internacionalização ao nível das empresas brasileiras. De fato, este estudo compreende o primeiro de uma série de estudos em desenvolvimento que procuram avaliar a experiência empresarial de internacionalização de empresas brasileiras à luz da Teoria das Dimensões Culturais de Hofstede, tal como revista por Ghemawat e Reiche (2011). Por empresas multinacionais brasileiras entende-se: (i) empresas de capital nacional que atuam no mercado externo e que possuam fábricas instaladas e faturem ao menos USD. 600 milhões ao ano; (ii) as atividades geradas no mercado externo correspondem a $40 \%$ de seu faturamento total. Tal é o caso das seguintes empresas: Embraer, Gerdau, Brasil Foods, JBS-Friboi, Petrobrás, Ambev, Vale, Sandálias Havaianas, dentre outras.

Os processos investigativos se dividiram em três pilares: (i) levantamento bibliográfico; (ii) seleção do case; (iii) construção do mapa conceitual. A seleção do caso único se seu por conveniência, uma vez que os autores puderam dispor de inúmeras informações relacionadas à empresa investigada. Os matizes teóricos foram apresentados de forma preliminar acima e serão escrutinados nas próximas seções. Isto foi feito por meio da discussão e análise das premissas de cada abordagem teórica-conceitual. O levantamento bibliográfico foi efetuado no âmbito de bases científicas junto à biblioteca virtual da USP (SibiNet), quanto no Portal de Periódicos da CAPES, que incorpora diversas bases de periódicos indexados, nacionais e internacionais. ${ }^{3}$ A construção do mapa conceitual baseou-se no cruzamento dos pontos de convergência e divergência das abordagens teóricas apresentadas. Este viabilizou a construção de uma matriz referencial que serviu de referência para o enquadramento do caso-piloto.

Em suma, com base na revisão da literatura acerca do fenômeno da internacionalização e seu emprego na avaliação de caso-piloto, o que se propôs foi a delimitação de um quadro teórico-conceitual destinado a vincular as contribuições da literatura para o entendimento do processo de internacionalização e multinacionalização ao nível das EMNs brasileiras. Ao fazer isto, foi feito um esforço no sentido de compreender o fenômeno da internacionalização à luz da teoria proposta por Hofstede (2011), posteriormente revista por Ghemawat e Reiche (2011). Como resultados, o que se estabeleceu foi uma investigação orientada na generalização e aprofundamento do entendimento dos processos de internacionalização de EMPED. Este objetivo foi perseguido a partir da análise das dimensões culturais nacionais e avaliação de sua influência sobre o processo. Finalmente, urge destacar que tal tema até o presente não foi aplicado no entendimento dos processos de internacionalização de empresas brasileiras.

\section{MODELOS CONSAGRADOS INTERNACIONALIZAÇÃ̃}

DE

Para o entendimento sob uma perspectiva mais ampla do quadro referencial teórico acerca das empresas multinacionais (EMNS), das EMPED e das EMNS Brasileiras buscou-se inicialmente explicitar a EMNS dos PED, posteriormente as EMPED em especial as latino-americanas e por último as brasileiras. O quadro referencial teórico acerca do processo de internacionalização das EMNS pode ser melhor sintetizado a partir de quatro perspectivas: (1) Modelo de Dunning (o qual possui duas vertentes

\footnotetext{
${ }^{3}$ ISI Web of Knowlwdge, Pro Quest e Scopus. Periódicos científicos consagrados foram consultados, entre estes: Academy of Management Review e Management Science; IEEE Transactions on Engineering Management; Industrial Marketing Management; International Journal of Project Management; International Institute for Learning; Journal of Construction Engineering and Management; Journal of Engineering and Technology Management; Journal Of Operation Management; Journal of Operational Research Society; Journal of Product Innovation Management; Project Management Journal; R\&D Management, Technovation; Research Policy; The Engineering Economist, dentre outros.
} 
Estratégias de Internacionalização de Empresas Multinacionais Brasileiras e Avaliação das Dimensões Culturais Nacionais: Estudo de Caso Setor de Fabricação de Implementos Agrícolas.

teóricas), (2) Teoria das Vantagens Locacionais Específicas, (3) Hipótese do Ciclo de Vida do Produto e (4) Outras Perspectivas Teóricas Ecléticas, incluindo denominada Teoria das Dimensões Culturais de Hofstede (2011) devidamente criticada, adaptada e relativizada pelas observações de Ghemawat e Reiche (2011).

\subsection{Modelo de Dunning}

O Modelo de Dunning (1997) possui duas vertentes; (i) paradigmas ecléticos e (ii) modelo dos caminhos do desenvolvimento dos recursos internacionais disponíveis para investimentos. A perspectiva dos Paradigmas Ecléticos é bastante interessante sob o ponto de vista da riqueza de abordagem. Esta busca explicar (i) os motivos da internacionalização, (ii) as principais estratégias adotadas com este objetivo e (iii) seus resultados. Para Dunning (1999), as EMNS buscam obter vantagens competitivas não compartilhadas no curto prazo pelos concorrentes dos países hospedeiros (PED). Entre estas, se destacam as vantagens tecnológicas de gestão, que exploram as denominadas vantagens da internacionalização (baseadas nos custos de mão de obra, redução de custos de fretes, por exemplo). Segundo esta abordagem, as vantagens de localização, sobretudo aquelas relativas a recursos naturais e certos tipos de vantagens comparativas também, são levadas em consideração na decisão de abertura de filias em outros países. Como corolário, Dunning (1998) propõe uma classificação para os IDE de acordo com a motivação. Esta é tipificada em quatro categorias: (i) resource seeking; (ii) market seeking; (iii) efficiency seeking; (iv) strategic asset seeking.

$\mathrm{Na}$ segunda onda de multinacionalização das empresas dos PCs, se o governo promover uma política industrial voltada para o mercado internacional, fomentando atividades exportadoras, as EMNS podem então desenvolver atividades inovadoras especificas do país hospedeiro, aproveitando melhor as vantagens comparativas baseadas nos recursos do país hospedeiro e incrementando o ingresso líquido de IDE.

Da segunda para a terceira onda ocorre o fenômeno da maturidade das vantagens comparativas de recursos e do incremento líquido dos IDE. Tal fenômeno proporciona a queda relativa das desvantagens de localização do país receptor ou hospedeiro. O resultado previsto é a consolidação de uma estrutura produtiva (autóctone) mais internacionalizada, alinhada racionalmente com as dotações de fatores do país.

O amadurecimento das características da terceira onda conduz a quarta onda de forma não linear e se caracteriza pela mudança de caráter do perfil dos investimentos das EMNS. Estes passam a se associar às metas globais da empresa matriz, que busca obter vantagens da coordenação entre suas filiais (efficiency seeking).

Os PED, na medida em que avançam em seu processo de desenvolvimento econômico, atinge eventualmente a quarta etapa. Nesta, geralmente se tornam emissores de IDE. Este fato se deve aos custos dos recursos locais se tornarem menos atrativos que outros países em estágios de desenvolvimento distintos, que oferecem recursos e incentivos a custos mais vantajosos. A posse de ativos estratégicos (skills, management, tecnologias avançadas, sistemas de informação diferenciados, etc.) também pode explicar o processo de incremento dos IDE. Também explica a transformação do país em emissor líquido de IED (Dunning; 1997).

Dunning (1997) evidencia a ascensão da denominada segunda onda de IDE dos PED e também o processo de paralisação de IDE, que corresponde à primeira onda nos processos de downsizings e fusões que caracterizaram a economia mundial da última década. Chudnovsky (2004) destacam que grande parte das vantagens das empresas da primeira onda de IDE era "país especifica" e, se originariam de barreiras de entrada. Estas permitiam aos países hospedeiros ou receptores a adaptação de tecnologias importadas para operar em pequena escala. Tal fato possibilitava o desenvolvimento da estratégia marketing seeking para as EMED destes países. A generalização do processo de globalização ensejou uma onda de abertura aos mercados externos, reduzindo as vantagens alcançadas durante a primeira onda.

\subsection{Teoria das vantagens locacionais específicas}

A teoria das vantagens locacionais específicas foi amplamente difundida no mainstream economic literature durante a década de 80 , sendo derivada da teoria convencional acerca das Empresas Transnacionais (ET). Com relação às EMPED a teoria das vantagens locacionais específicas representa uma aplicação da teoria convencional acerca das ET em geral às EMPED, conforme Yeung e Chung (1999). A teoria das vantagens locacionais específica postula que as EMPED possuem baixas ou temporárias vantagens devido ao seu tamanho e perfil tecnológico. As EMPED dependem fortemente de vantagens locacionais específicas de seus respectivos países de origem ou de seus hospedeiros. As vantagens locacionais específicas das EMPED são derivadas de duas características do progresso tecnológico (Lall, 1983; Chudnovsky, 2004). A primeira é a localização da mudança técnica no nível microeconômico, alcançada por intermédio de aproveitamentos de economias de escala e inovações tecnológicas implantadas pelas EMNS dos PC. Este fenômeno geralmente ocorre por meio de joint-ventures, alianças e parcerias estratégicas e, em muitos casos, por intermédio de fusões e posteriores spins offs. 
Estratégias de Internacionalização de Empresas Multinacionais Brasileiras e Avaliação das Dimensões Culturais Nacionais: Estudo de Caso Setor de Fabricação de Implementos Agrícolas.

A segunda característica diz respeito à irreversibilidade de tais mudanças técnicas. Uma vez incorporadas pelas EMPED estas mudanças não podem ser revertidas facilmente pelos seus altos custos de saídas e a alternativa é a evolução progressiva por meio da incorporação de técnicas correlacionadas. As EMPED ganham assim vantagens competitivas por meio de sua competência em adaptar capacidades técnicas das EMNS dos PC (Aggarwal; Ghauri, 1993; Dunning, 1995, 1997).

\subsection{Hipótese do ciclo de vida do produto}

A hipótese do ciclo de vida do produto tem suas origens no chamado Modelo Hymer- Kindleberger (2002). As EMNS dos PCs veem-se limitadas em termos de crescimento de seu market share no mercado doméstico (não obstante, o gigantismo do mercado americano). Por esta razão, buscam aumentar sua participação no mercado internacional por meio de da produção, nos respectivos países destino, de suas exportações. O resultado é a obtenção de maiores vantagens competitivas em função de redução de custos de transporte e custos a estes associados (fretes internacionais, seguros, Duty tax e Value-added tax, barreiras de entrada, outros custos de distribuição, custos de mão de obra e insumos, dentre inúmeros outros). As EMNS dos PCs procuram obter vantagens específicas de localização produzindo nos respectivos países destino de suas exportações. Este fenômeno corresponde a "primeira onda" de multinacionalização nos PED por substituição de importações.

Segundo Vernon (1966) as EMNS americanas aperfeiçoavam suas competências encurtando o ciclo de vida de seus produtos buscando obter maiores vantagens competitivas advindas do lançamento de novos produtos e esta estratégia também se traduzia em termos de seus ciclos de investimentos (Michalet, 1984). A HCVP contempla cinco estágios: (i) exportações das EMNS (a partir dos países emissores ou de origem); (ii) abertura de escritório de representações; (iii) abertura de depósitos ou armazéns logísticos; (iv) instalação de fábricas; (v) expansão para mercados vizinhos. Yeung e Chung (1999) generalizam o HCVP, expandindo-o como meio de tipificar as fases do processo de multinacionalização (quadro 1)

\begin{tabular}{|c|l|l|}
\hline TIPO DE FASE & \multicolumn{1}{|c|}{ CARACTERÍSTICAS } & \multicolumn{1}{|c|}{ RESULTADOS } \\
\hline $\mathbf{1}$ & $\begin{array}{l}\text { Lançamento do Produto, sem vendas domésticas, sem } \\
\text { exportações. }\end{array}$ & Custos de Start up. \\
\hline $\mathbf{2}$ & $\begin{array}{l}\text { Início das vendas no mercado doméstico } \\
\text { Volume dependente da capacidade ou da } \\
\text { demanda do mercado doméstico }\end{array}$ \\
\hline $\mathbf{3}$ & $\begin{array}{l}\text { Demanda doméstica cresce a taxas decrescentes, início do } \\
\text { processo de exportações para países similares ou menos } \\
\text { desenvolvidos. }\end{array}$ & Sem produção além-mar \\
\hline $\mathbf{4}$ & $\begin{array}{l}\text { Esgotamento do crescimento das vendas no mercado doméstico } \\
\text { e início da produção em países menos desenvolvidos }\end{array}$ & Incremento das vendas inter company \\
\hline $\mathbf{5}$ & $\begin{array}{l}\text { Vendas domésticas continuam vendas para países similares ou } \\
\text { menos desenvolvidos são atendidas pela produção local, vendas } \\
\text { de inovação são exportadas para os países menos } \\
\text { desenvolvidos. }\end{array}$ & $\begin{array}{l}\text { Inovações são deslocadas para subsidiárias de } \\
\text { diversos países }\end{array}$ \\
\hline $\mathbf{6}$ & $\begin{array}{l}\text { Exportaç̃̃es de vendas de produtos inovativos declinam demais } \\
\text { países são começam a exportar estas vendas }\end{array}$ & $\begin{array}{l}\text { Exportações para países menos } \\
\text { desenvolvidos são realizadas por outras } \\
\text { subsidiárias fora dos países centrais }\end{array}$ \\
\hline $\mathbf{7}$ & $\begin{array}{l}\text { Exportações de vendas de produtos inovativos declinam nos } \\
\text { países de origem }\end{array}$ & $\begin{array}{l}\text { Países menos desenvolvidos absorvem estas } \\
\text { vendas de produtos inovativos }\end{array}$ \\
\hline
\end{tabular}

Quadro 1 - Fases da hipótese do ciclo de vida do produto expandida. Fonte: Adaptado de Yeung e Chung (1999).

Há outra vertente teórica da HCVP expandida. Esta é denominada abordagem picking order (Wells, 2003). Tal tipologia busca classificar os países emergentes de acordo com o seu nível de desenvolvimento econômico e grau de sofisticação tecnológica. Segundo esta concepção teórica, dois fatores são críticos para explicar o movimento dos IDE entre as economias dos PED: (i) gap5 tecnológicos; (ii) fator custos. Os gaps tecnológicos são relativos aos níveis diferentes de padrões tecnológicos existentes entre as economias dos países emergentes, por exemplo, as desigualdades tecnológicas entre Brasil e Bolívia ou entre Taiwan e Indonésia.

\section{ABORDAGEM DA ESCOLA NÓRDICA}

Nos anos 70, alguns pesquisadores da Universidade de Uppsala (Hörnell, Vahlne; 
Estratégias de Internacionalização de Empresas Multinacionais Brasileiras e Avaliação das Dimensões Culturais Nacionais: Estudo de Caso Setor de Fabricação de Implementos Agrícolas.

Wiedersheim-Paul, 1973; Johanson; WiedersheimPaul, 1974; Johanson E Vahlne, 1977, 1990; 2003) concentraram esforços de pesquisa no processo de internacionalização de firmas suecas manufatureiras e desenvolveram um modelo explicativo para entender como essas firmas escolhiam mercados e formas de entrada quando tomavam tal decisão. A pesquisa foi influenciada pela teoria da firma de Cyert e March (1963), Aharoni (1966) e Penrose (1995).

Segundo esta concepção, o processo de internalização é visto como decorrente das experiências de sucesso, alcançadas em mercados receptivos às empresas suecas, com histórico de lucratividade. Cabe destacar a ausência de planejamento decorrente deste processo, que se deu de forma incremental (Johanson; Vahlne, 1977).

A sequência de modos de operação se inicia por exportação direta, quando se tem a oportunidade de adquirir conhecimentos sobre o novo mercado. $\mathrm{O}$ envolvimento se aprofunda a partir do aumento desses conhecimentos e da melhoria dos canais de informação, podendo a firma chegar a um alto envolvimento, representado pelo estabelecimento de subsidiárias no país estrangeiro. A incerteza em relação ao resultado de uma ação aumenta com a distância da matriz até o mercado da filial. Contudo, a natureza do processo reduz esta, estimulando as decisões e alocação de recursos estratégicos.

Vahlne; Wiedersheim-Paul (1973) tentaram identificar fatores que influenciavam a distância psíquica entre Suécia e outros países. Esta foi definida como a soma dos fatores que interferiam no fluxo de informação entre países. Concluíram que a distância psíquica entre a Suécia e um mercado estrangeiro determinado era influenciada pelos fatores: (i) nível de desenvolvimento, (i) nível de educação, (iii) linguagem de negócios, (iv) diferenças culturais, (v) linguagem cotidiana e vínculos existentes entre o país de origem e o mercado estrangeiro (Carlson, 1975). Ao incorporar aspectos comportamentais associados às decisões de investimento, estes autores incrementam o entendimento da dinâmica de IED em nível microeconômico. Adicionalmente, Nordström; Vahlne (1985); Nordström (1991) introduziram no modelo a importância do tamanho do mercado e de outros determinantes econômicos no processo de internacionalização da firma. Johanson; Mattson (1988), afirmam que o modelo de internacionalização é menos eficiente quando existe uma situação na qual mercado e firma são altamente internacionalizados. A internacionalização gradual não era um fenômeno exclusivamente sueco, pois, o mundo se internalizava em larga escala pelo crescimento das filiais de empresas americanas e europeias na América Latina, Ásia e até mesmo na África. Isto explica em grande medida o fluxo de comércio e de IED que o acompanha.

\subsection{Escola Nórdica (redes de relacionamento)}

Para Hemais e Hilal (2003) a questão das redes de relacionamentos (networks) é considerada uma evolução natural do pensamento da Escola Nórdica. Segundo estes autores seus seguidores têm desempenhado papel central no desenvolvimento da perspectiva industrial, focalizando os relacionamentos existentes entre firmas e mercados industriais. Assim, Johanson e Mattsson (1988) afirmam que os fatores e as forças competitivas em indústrias altamente internacionalizadas, criam um padrão heterogêneo de oportunidades de entrada. Essa heterogeneidade motivará a firma a escolher mercados e estratégias de entrada, que poderão ser bem diferentes do que é previsto pelo modelo tradicional de Uppsala. As próximas subseções apresentam o que no presente estudo se denominou questões controversas associadas à ótica da Escola Nórdica

\subsubsection{Paradoxo da distância psíquica}

Segundo Nordstrom e Vahlne (1992), o fator distância psíquica se baseia, em parte, nas dimensões culturais apontadas pelo pesquisador holandês Hofstede (1980). Assim, termos distância psíquica e distância cultural são usados como sinônimos, embora o primeiro seja um pouco mais amplo, uma vez que inclui um componente de preocupação com as dificuldades inerentes aos negócios, ausente no conceito puro de distância cultural.

Para Hemais e Hilal (2003), individualmente os tomadores de decisão têm que gerenciar os seguintes fatores causais: (i) influência das networks como redutoras do sentimento de ansiedade; (ii) realidade das percepções assimétricas, que fazem com que a distância psíquica de A para B possa não ser igual que a de $\mathrm{B}$ para A; (iii) paradoxo de distância psíquica, que pode fazer com que a percepção de baixos níveis de ansiedade ou de maior similaridade, como alguns autores preferem, funcione como uma barreira à percepção.

Segundo Pitelis (2003) o paradoxo da distância psíquica faz com que a percepção de aparente similaridade possa levar à aceitação de estereótipos de familiaridade e proximidade, e isso acaba resultando em níveis de desempenho indesejados ou, diretamente, no fracasso das operações. Para Nordstrom e Vahlne (1992) os obstáculos apontados podem ser superados por meio de um processo de aprendizagem e de conscientização das limitações inerentes às percepções individuais. Em síntese, de acordo com a literatura, a distância psíquica, percebida pelo executivo, afeta a sua análise de variáveis como barreiras a exportação, risco das operações, avaliação do potencial do mercado, confiança na possibilidade de sucesso, formação de 
networks sociais e políticas, entre outras (Hemais; Hilal, 2003).

\subsubsection{Internacional como processo sem continuidade e aleatório}

De acordo com a Escola de Uppsala, as firmas se expandem para o exterior por meio de uma série de investimentos graduais e incrementais, à medida que ganham experiência no novo mercado que escolheram para atuar. Entretanto, conforme a Escola Nórdica, o processo de internacionalização é descontínuo, ao invés de incremental (Pedersen; Shaver, 2000).

Para Hemais e Hilal (2003) essas teorias de investimento direto consideram que, em um primeiro momento, as firmas enfrentam desvantagens nos mercados externos, quando competem com firmas locais. As desvantagens são função de uma ampla gama de motivos: (i) diferenças culturais e de idioma; (ii) distinção no funcionamento das instituições, leis e forma de sua aplicação (enforcement); (iii) diferenciações no contexto e ambiente de negócio; (iv) presença de discriminação (real ou aparente) por parte do governo local; (v) flutuações na taxa de câmbio, entre outras. (Hymer, 1976). Assim, a movimentação de capitais enfrenta fricções e os investidores estrangeiros devem encontrar formas de superar essas barreiras, de modo a poderem competir com sucesso no novo mercado, a teor de Wells (2003).

\subsection{Teoria das dimensões culturais de Hofstede}

Outra perspectiva teórica dedicada a explicar o processo de internacionalização das empresas a partir das diferenças culturais nacionais entre países e seu impacto no processo decisório e, consequentemente na operação das empresas que se internacionalizam e tornam-se empresas multinacionais e ou transnacionais, é a Teoria das Dimensões Culturais do psicólogo social holandês Geert Hofstede conforme Minkov e Hofstede (2012)

Minkov e Hofstede (2012) realizaram uma pesquisa junto aos empregados IBM entre 1967 e 1973 em mais de 50 culturas de países diferentes. A análise de respostas de mais de 116 mil empregados da IBM, baseadas em questões acerca de suas ocupações e emprego revelaram diferenças culturais sistemáticas por meio de quatro dimensões: (i) distância do poder; (ii) individualismo/coletivismo; (iii) mitigação de incertezas; (iv) masculinidade/feminidade. Provavelmente a dimensão cultural mais importante identificada na pesquisa de Hofstede (1976) foi a distância de poder, que concerne o grau ao qual uma cultura aceita e reforça o fato que o poder é distribuído desigualmente na sociedade. Os membros de altas culturas de distância de poder como a Malásia aceitam diferenças de posição e é esperado mostrar o respeito próprio aos seus superiores. As diferenças de posição existem dentro da hierarquia organizacional, sendo mais acentuadas nas culturas asiáticas que nas culturas ocidentais, notadamente a europeia e dos EUA.

Para Ghemawat e Reiche (2011) a dimensão cultural mais importante identificada na pesquisa de Hofstede (1976) é a distância de poder, que concerne o grau ao qual uma cultura aceita e reforça o fato que o poder é distribuído desigualmente na sociedade. Os membros de altas culturas de distância de poder como a Malásia aceitam diferenças de posição e são esperados demostrar o respeito próprio aos seus superiores. As diferenças de posição existem dentro da hierarquia organizacional, mas eles também podem ser baseados em idade, classe social, ou papel de família. É importante observar que, embora essas diferenças sempre sejam evidentes, nas culturas asiáticas e de outros países emergentes. Em uma cultura onde a distância do poder é alta, um superior tratará aqueles de níveis mais baixos com a dignidade. Em culturas de distância de poder baixas, como a Dinamarca, a maior participação na tomada de decisão independe da distância do poder e do nível hierárquico. O conceito da distância do poder ajuda a explicar a importância do envolvimento amplo dos empregados no processo decisório, independente da hierarquia nas culturas ocidentais. Também se aplica nas culturas asiáticas, onde a hierarquia é mandatória no processo decisório e tem impacto direto nas decisões de multinacionalização das empresas e nas operações do dia a dia.

A pesquisa, baseada em valores culturais foi levada a cabo por, Minkov e Hofstede (2012) também foi usada para avaliar as distâncias culturais agregadas entre países ao longo dessas quatro dimensões. Embora esse grande número de distância cultural tenha sido largamente usado para explicar fenômenos diferentes no negócio internacional como modo de entrada, diversificação seletiva, grau de internacionalização, e multinacionalização, esta aproximação também foi criticada. Inicialmente, o cálculo de distâncias baseadas em grande número amostras de sugere que as distâncias sejam simétricas. Em outras palavras, pensa-se que um investimento sueco na China enfrenta exatamente a mesma distância cultural que um investimento chinês na Suécia. Tal suposição exigia alguma forma de comprovação empírica. Por outro lado, a pesquisa de valor cultural de Hofstede (1980) também foi empregada como meio de computar distâncias culturais agregadas entre países ao longo dessas quatro dimensões (distância do poder, grau de individualismo/coletivismo, grau de aversão à incerteza e prevalência da masculinidade/feminilidade) como meio de quantificar diferenças culturais entre esses países e o impacto destas no processo decisório de internacionalizar e ou 

Culturais Nacionais: Estudo de Caso Setor de Fabricação de Implementos Agrícolas.

investir em outras localidades. Embora esse grande número de formas de distância cultural tenha sido largamente aplicado para explicar fenômenos diferentes no negócio internacional (modo de entrada diversificação seleta de internacionalização, realização de estratégias de multinacionalização, etc.), esta aproximação teórica também foi largamente criticada.

De qualquer forma a teoria de Hofstede, baseada em sua pesquisa e estudo de caso único (case IBM), busca explicar o fenômeno da internacionalização por meio das quatro dimensões, o impacto de fatores culturais no processo decisório das empresas e como estes influenciam as estratégias de internacionalização e ou multinacionalização em curso. Ghemawat e Reiche (2011) afirmam que a teoria de Minkov e Hofstede (2012) é uma importante contribuição do entendimento de como os fatores culturais influenciam as decisões de investimento, multinacionalização e o próprio processo decisório na gestão das operações do dia a dia das empresas, não explorado por Dunning (1993; 1994; 1997; 1998).

\section{EMPRESAS E GRUPOS ECONÔMICOS LATINO-AMERICANOS}

As economias latinas americanas, em geral foram objetos de estudos relevantes em termos do papel das EMNS, são: Argentina, Brasil, Chile e México (Chudnovsky; López, 1999). Neste grupo de países, nos anos 50 e 60 ocorreu o processo de industrialização substitutiva de importações, o qual foi protagonizado por grandes grupos econômicos nacionais e as EMNS dos países centrais (PC) sob a coordenação e em muitos casos, com forte participação dos Estados Nacionais. Tais economias têm muitas tendências comuns, com relação ao processo de industrialização baseado na substituição de importações. Estes se inserem na "primeira onda" de multinacionalização. Outro fator comum é que nos anos 90 foi maior o grau de abertura aos fluxos de comércio, capitais, tecnologias, P\&D e outras conveniências, comparativamente aos anos 70 e 80 . É interessante observar que o Brasil se abre mais tardiamente e é a mais fechada dentre as economias. Já o Chile se abriu mais precocemente e atualmente é mais aberta das economias, ficando o México e a Argentina em posição intermediária.

\subsection{Processo de internacionalização e multinacionalização}

Os processos de internacionalização das empresas dos países latinos americanos remontam o modelo agroexportador no início do século. Também tem como fator determinante o amplo mercado interno. As capacidades adaptativas, modelos de gestão flexíveis, uma gestão comercial agressiva, etc., permitia que empresas radicadas nestas regiões competissem com sucesso no mercado externo, principalmente se ajustando às necessidades dos clientes dos mais diversos locais. É interessante observar que em 1980 a Argentina detinha a primazia como grande emissor de IDE dentre os PED com cerca de USD 1 bilhão, somente ficando atrás de Hong Kong (Chudnovsky; López, 1998). Brasil e Chile detinham cerca de USD \$ 200 milhões (dados da UNTAD de 1993).

Nos anos 90 também é possível constatar a existência de investimentos de alguns grupos de autopeças brasileiros nos EUA e Europa, aproximadamente USD 50 bilhões. $\mathrm{O}$ atraso relativo do Brasil nesta questão pode ser atribuído aos fatores retro mencionados e também a ocorrências tardias das reformas e do processo de privatização. A falta de entendimento e percepção de que a preservação dos mercados locais depende em larga instancia de se competir com êxito nos principais mercados mundiais, conforme Chudnovsky (2004).

\subsection{Perfil das empresas investidoras Latino- americanas}

Enquanto as EMNS dos países latino americanos faturam anualmente entre USD 800 e USD 900 milhões, as equivalentes da Ásia faturam entre USD 80 e 120 bilhões. Outra característica que distingue as EMNS dos países latino americanos das EMNS dos países asiáticos é o fato de estas últimas diversificarem seu faturamento de forma expressiva para o resto do mundo e não apenas para países vizinhos, como ocorre com as EMNS dos primeiros. (Chudnovsky; López, 1998).

No Brasil, as principais empresas vinculadas ao processo de internacionalização estão vinculadas a grandes grupos econômicos de governança familiar, em transição para formas de controle e gestão mais profissionalizadas, com intervenções de participação no controle acionário de fundos de pensão, recentemente são outras características predominantes. É muito comum estas empresas atuarem em setores commoditizados, muitas vezes vinculadas a posse de recursos naturais (cimento, vidro, petróleo, bancos, engenharia de construção, bebidas e alimentos, hotelaria, televisão, entretenimento e transportes). Alguns podem também refletir vantagens comparativas mais especificas de cada país (como os segmentos de fármacos e siderurgia na Argentina). Papel e cobre, bem como do complexo florestal madeireira, previdência social e comercio no Chile. Agro e biotecnologia, televisão, telecomunicações e equipamento de transporte no México.

Enfim pode-se numa classificação preliminar afirmar que as empresas multinacionais latino americanas atuam basicamente em setores resource seeking e marketing seeking, sendo exceções as que 
Estratégias de Internacionalização de Empresas Multinacionais Brasileiras e Avaliação das Dimensões Culturais Nacionais: Estudo de Caso Setor de Fabricação de Implementos Agrícolas.

atuarem com foco nas estratégias efficiency seeking $e$ strategic asset seeking e geralmente nestes últimos casos trata-se de alianças estratégicas e joint ventures.

\subsection{Estratégias de internacionalização e multinacionalização das EMNs Latino-americanas e brasileiras}

Dentro da lógica evolutiva e classificatória do Modelo de Dunning (1998) consideram os IDE das EMNS da América Latina como dirigidos por estratégias market seeking, ressaltando-se o fato de que as empresas buscam mercados maiores e com maiores perspectivas de crescimento e sustentabilidade, em detrimento de mercados regionais localizados, de baixa demanda e alto risco como nas fases anteriores do processo de internacionalização.

A estratégia de resource seeking é muito comum na indústria petrolífera (Brasil, Argentina, Venezuela, México), porém cabe destacar que o fator tecnológico e skills é condição necessária para esta estratégia. Isto explica, ao menos parcialmente, as alianças estratégicas da YPF, Petrobrás, PEMEX e Petróleo de Venezuela. Empresas brasileiras do segmento alimentício e de insumo básicos se baseiam em estratégias resource seeking, notadamente em suas operações na Argentina, bem como algumas empresas chilenas de agro reflorestamento e mineração (inclusive na Patagônia Argentina).

Grande parte das empresas multinacionais latinos americanas atua por meio de da estratégia market seeking de forma local, regional ou global (Yeung; Chung, 2005). De forma local a grande maioria limitando-se a países limítrofes. Outra parte seletiva atua de forma regional com atividades e plantas em todo o continente, e poucas atuam de forma global. Aquelas que o fazem em muitos casos é por necessidade de extensão de suas atividades por escala, mais do que por estratégias sofisticadas. As que se utilizam de estratégias do tipo efficiency seeking são poucas e heterogêneas e buscam a liderança em seus respectivos segmentos (Sabó, Techint, Siam, Cemex, La Moderna, Seminis), além de uma integração mais complexa em decorrência das particularidades da competição em seus setores.

A predominância da estratégia market seeking é compreensível, pois para competir em outros patamares estratégicos é necessário mais capital, maior nível de aprendizagem, menores barreiras, maiores custos de adaptação e isto nem sempre está ao alcance destas empresas ou não é atrativo na conjuntura. As poucas empresas que atuam da forma strategic asset seeking geralmente o fazem por meio de parcerias e alianças estratégicas. A operação em países limítrofes e ou mais distantes dentro do continente é operacionalizada em muitos casos pela compra de outras empresas dos países receptores e representam um importante acesso a ativos estratégicos (Chudnovsky, 2004; Yeung; Chung, 2005)

\subsection{Resultados do processo de internacionalização para empresas e países}

A análise de quatro países, Argentina, Brasil, Chile e México, à luz das contribuições de Chudnovsky (2004), permite inferir que para as empresas analisadas os benefícios foram bastante amplos em termos de: (i) aceleração no desenvolvimento de tecnologias, (ii) acesso de fontes mais baratas de crédito internacional; (iii) crescimento dos skills e sistemas de gestão; (iv) aumento da qualidade dos processos (defeito zero em muitos casos); (v) acesso a ativos estratégicos essenciais como meio de competir no mercado internacional; (vi) alcance de ganhos á escala e vantagens de custos compartilhadas. Como resultado, muitas empresas transitaram do estágio resource seeking (Petrobrás, YPF, CVRD, Pemex) para o marketing seeking (Itaú Garantia, Odebrecht, Cemex, Socma, Bimbo Gerdau). Outras passaram a figurar na fronteira do efficiency seeking (La Moderna Seminis, Pathfinder, Des/Agrobios).

Por outro lado, não há consenso sob o ponto de vista dos países emissores, no Brasil a pouca relevância do fenômeno adiou um balanço mais rigoroso do papel do IDE ao exterior. Na Argentina e México o debate é incipiente, porém aventa-se que são no sentido de tal fenômeno tem caráter desenvolvimentista e há um aumento do valor agregado doméstico bem como da formação bruta de capital fixo, além de inúmeros benefícios para a população em termos de melhor qualidade da oferta. No Chile o impacto do IDE junto ao balanço de pagamentos é altamente positivo, em função de seu alto percentual de financiamento no mercado externo $(100 \%)$.

\subsection{Perfil das empresas Latino-americanas e brasileiras à luz das abordagens de Hofstede e Ghemawat e Reiche}

Para Ghemawat e Reiche (2011), as empresas latino americanas, em geral, e especificamente as brasileiras, possuem uma cultura de internacionalização de alto nível que respeita às boas práticas de gestão e assume o modelo global de multinacionalização de forma específica. Para os referidos autores a influência das dimensões culturais de Hofstede (2011) tem a hegemonia do fator grau de aversão das incertezas, sendo neste caso considerado alto. Prevalece também, não obstante a aceitação por parte destas empresas das boas práticas e do modelo global de governança corporativa, o aspecto masculinidade/feminilidade, sendo o primeiro claramente hegemônico em relação ao segundo. $\mathrm{O}$ 

Culturais Nacionais: Estudo de Caso Setor de Fabricação de Implementos Agrícolas.

fator distância do poder é considerado de médio para baixo com relação ao processo decisório e o fator individualismo prevalece de forma absoluta sobre o coletivismo no comportamento decisorial dos executivos. Finalmente, cabe adiantar que a tipologia de Hofstede (2011) será muito útil para o entendimento do perfil dos executivos brasileiros e o entendimento do clima organizacional nas empresas brasileiras que se multinacionalizaram recentemente, vivendo ainda sob o paradigma de um modelo familiar de gestão, em transição para uma governança globalizada.

\section{CASO-PILOTO}

O estudo de caso objeto deste artigo teve como unidade de análise uma empresa multinacional de capital com origem $100 \%$ brasileira que atua no setor de fabricação de implementos agrícolas. Possui um faturamento superior a 1,5 bilhões de dólares por ano e mais de 1,5 mil colaboradores e empregados. Empresa com uma estrutura organizacional do tipo linear funcional não possui grande número de filiais e atua em pouco mais de 15 países, em sua grande maioria no continente africano e américa central. Possui uma das maiores redes de distribuição de implementos agrícolas de atacado e varejo do país. Recentemente saiu de uma crise financeira. Passou por um processo de reestruturação total. Atualmente, substitui um modelo de governança familiar por modelo de governança corporativa globalizado em fase de transição. Está em fase de implantação do Sistema de Manufatura Enxuta, notadamente em suas linhas de montagem e soldagem. As áreas de fundição, forjamento a quente e a frio estão excluídas do projeto lean por questões de priorização estratégica.

Dentro da lógica evolutiva e classificatória do Modelo de Dunning (1997) consideram-se os IDE desta EMN Brasileira orientados por estratégias do tipo market seeking, com maiores perspectivas de crescimento e sustentabilidade em mercados globais, extrapolando as limitações da estratégia de crescimento anterior (resource seeking), aplicada em seus passos primordiais do processo de internacionalização. Esta tinha como foco países limítrofes, já apresentando mercados limitados e saturados. A empresa hoje atua em 10 países do mercado africano, e 7 países da américa latina. O redirecionamento para estratégia market seeking é justificada, devido ao fato de ser necessário para competir em patamares estratégicos globais uma curva de aprendizagem mais sofisticada, uma cultura corporativa mais globalizada, competências logísticas mais eficientes, áreas de produto e marketing mais integradas, maior expertise na gestão de facilidades e uma gestão financeira, contábil e tributária mais adaptável e flexível.

Algumas filiais da empresa atuam em conformidade com a estratégia strategic asset seeking, e geralmente o fazem por meio da formação de parcerias e ou alianças estratégicas com escritórios locais de representação no ocidente europeu e nos EUA. A operação em países limítrofes e ou mais distantes, dentro do continente, é operacionalizada em muitos casos pela compra de participações em outras empresas dos países receptores e representam um importante acesso a ativos estratégicos, tal como apontado por Chudnovsky (2004) e Yeung e Chung (2005). Todavia, recentemente observa-se a compra de concorrentes e parceiros na África ocidental, o que denota um ponto de inflexão e a ascensão da estratégia strategic asset seeking sobre a estratégia marketing seeking.

A partir dos pressupostos da Escola Nórdica, pode-se observar no estudo de caso, objeto deste artigo, que para os executivos a influência das networks e das estruturas correspondentes reduzia o sentimento de ansiedade e desconhecimento do ambiente. Por outro lado, há indícios que a realidade das percepções assimétricas, que fazem com que a distância psíquica de $\mathrm{A}$ para $\mathrm{B}$ possa não ser igual a distância de B para A, sofreram reversão. Ainda o paradoxo de distância psíquica, que podia fazer com que a percepção de baixos níveis de ansiedade ou de maior similaridade, como alguns autores preferem, sofreu modificação reduzindo a chamada barreira de percepção.

Sob o ponto de vista da Escola Nórdica verificou-se que o fator networking é preponderante para a maioria das filiais da empresa objeto do estudo de caso.

Sob a ótica da teoria das dimensões culturais de Hofstede (2011), há indícios que a empresa possui a prevalência da aversão às incertezas como principal driver cultural, sendo forte a influência do fator masculinidade sobre $\mathrm{o}$ fator feminilidade. $\mathrm{O}$ fator distância do poder é bastante discreto e os índices de participação dos empregados no poder decisório passaram a crescer substancialmente com a ampliação das operações no exterior. $\mathrm{Na}$ realidade $\mathrm{o}$ fator individualismo/coletivismo passou a ser determinante no processo decisório. Como consequência este passou a ter um efeito suavizador sobre uma suposta concentração do poder pelo fator distância do poder. $\mathrm{Na}$ verdade, isto evidencia uma lacuna no modelo das dimensões culturais de Hofstede (1980), a dimensão individualismo/coletivismo é claramente preponderante para o individualismo nas empresas brasileira e neutraliza a preponderância do fator distância do poder. 
Estratégias de Internacionalização de Empresas Multinacionais Brasileiras e Avaliação das Dimensões Culturais Nacionais: Estudo de Caso Setor de Fabricação de Implementos Agrícolas.

\begin{tabular}{|c|c|}
\hline \multicolumn{2}{|r|}{ MODELO DE DUNNING } \\
\hline 1. Background & $\begin{array}{l}\text { Padrão de operação reúne, sintetiza e tipifica características de diferentes arranjos/estratégias de inversão } \\
\text { externa. }\end{array}$ \\
\hline 2. Síntese abordagem & $\begin{array}{l}\text { Modelo prevê a seguinte tipologia de estratégias: resource seeking, market seeking, efficiency seeking, } \\
\text { strategic asset seeking }\end{array}$ \\
\hline \multirow{3}{*}{$\begin{array}{l}\text { 3. Revisão estratégia } \\
\text { por meio do modelo }\end{array}$} & $\begin{array}{l}\text { Adoção de opção ao aporte de recursos para obtenção do controle grandes rebanhos e pastagens, bem } \\
\text { como uso mais eficiente dos canais de distribuições e logística. }\end{array}$ \\
\hline & $\begin{array}{l}\text { Diversificação de atuação em mercados que tendem a ser mais exigentes contribuindo para amplificar a } \\
\text { escala das operações e ampliar o mix de produtos ofertados. }\end{array}$ \\
\hline & Estratégia de integração vertical \\
\hline \multicolumn{2}{|r|}{ HIPÓTESE DO CICLO DE VIDA DO PRODUTO - HCVP } \\
\hline 1. Background & $\begin{array}{l}\text { Padrão de operação parece conjugar estratégias que afetam a rentabilidade por meio da diversificação das } \\
\text { fontes de receitas e redução de custos por meio da otimização de processos econômico-financeiros }\end{array}$ \\
\hline 2. Síntese abordagem & As empresas operam em função de ciclos de produtos, hoje cada vez mais encurtados. \\
\hline \multirow{7}{*}{$\begin{array}{l}\text { 3. Revisão estratégia } \\
\text { por meio do modelo }\end{array}$} & Ampliação e diversificação dos mercados de atuação \\
\hline & Incremento da rentabilidade, redução e mudança do grau de versão aos riscos \\
\hline & Redução de custos logísticos \\
\hline & Redução de fricções associadas à exposição às barreiras fitossanitárias \\
\hline & Busca de redução de custos tributários e maior eficiência em Compliance. \\
\hline & Ganho com operações de arbitragem cambial \\
\hline & Acesso a insumos modernos aumento de eficiência em processamento e logística \\
\hline \multicolumn{2}{|r|}{ ESCOLA NÓRDICA } \\
\hline 1. Background & $\begin{array}{l}\text { Padrão de operação está orientado a busca de ganhos alcançados por meio de acesso a redes de produção } \\
\text { que geram economias de diversificação se orientam aos mercados de atacado e varejo }\end{array}$ \\
\hline 2. Síntese abordagem & As empresas se multinacionalizam em função de sua rede de relacionamentos no mercado internacional. \\
\hline \multirow{5}{*}{$\begin{array}{l}\text { 3. Revisão estratégia } \\
\text { por meio do modelo }\end{array}$} & Estabelecimento orientado onde a alta gestão participa de redes \\
\hline & $\begin{array}{l}\text { Conquista de mercados altamente competitivos e diversificados (nos EUA: incremento do mix de } \\
\text { produtos e perfil mais exigente do consumidor) }\end{array}$ \\
\hline & Segmentos alvo ditam as regras dos padrões de operação em escala global (idem) \\
\hline & $\begin{array}{l}\text { Garantia de contato com padrões de produção e oferta que tendem a influenciar os padrões fitossanitários } \\
\text { internacionais (inversões nos EUA e na Europa: consolidação de cultura global) }\end{array}$ \\
\hline & Busca de ampliação e consolidação das operações no oriente (Idem inversões na Rússia ....) \\
\hline \multicolumn{2}{|r|}{ TEORIA DAS DIMENSÕES CULTURAIS DE HOFSTEDE } \\
\hline 1. Background & $\begin{array}{l}\text { Padrão de operação orienta-se no sentido flexibilizar meios de operação imprescindíveis para competir de } \\
\text { forma assertiva em mercados globais }\end{array}$ \\
\hline 2. Síntese abordagem & $\begin{array}{l}\text { Masculinidade/Feminilidade, distância do poder, individualismo/coletivismo e aversão ao risco são } \\
\text { variáveis determinantes no processo de gestão internacional das empresas. }\end{array}$ \\
\hline \multirow{3}{*}{$\begin{array}{l}\text { 3. Revisão estratégia } \\
\text { por meio do modelo }\end{array}$} & $\begin{array}{l}\text { Estratégia de operação em mercados globais implica em gestão assistida marcada por tendência de } \\
\text { democratização dos processos decisórios }\end{array}$ \\
\hline & Interação com outras culturas induz a mudança na percepção dos agentes quanto à distância do poder \\
\hline & $\begin{array}{l}\text { Operar em escala global provoca alterações no perfil e grau de percepção aos riscos e maior transparência } \\
\text { e flexibilidade dos processos decisórios }\end{array}$ \\
\hline
\end{tabular}

Quadro 2 - Matriz de enquadramento do case-piloto.

Fonte: Elaborado pelos autores. 


\section{CONSIDERAÇÕES FINAIS}

No estágio atual de seu desenvolvimento, as empresas brasileiras de grande porte, com padrão de excelência e classe mundial para operar internacionalmente em escala global têm como uma opção estratégica, para muitas de suas empresas, a internacionalização e ou multinacionalização. Muitas destas estratégias configuram condição de crescimento e garantia de sobrevivência. Empresas que se internacionalizam obtém maior valor agregado para suas exportações, acessos a novos mercados e incorporam e ou desenvolvem novas tecnologias, reestruturam seus processos de produção, incrementam seus canais de distribuição, obtém linhas de crédito de menor custo e amplitude e qualificam melhor sua gestão e suas equipes de profissionais e executivos.

A internacionalização das EMNS brasileiras foi acompanhada de maior abertura comercial e econômica, o que por sua vez aprofundou e enriqueceu os conteúdos dos processos de internacionalização, possibilitando a queima de etapas de desenvolvimento para alguns países da região.

O Estudo de Caso pode evidenciar por meio de caso único, alguns pressupostos da teoria e revelar características essenciais da estratégia market seeking e efficiency seeking o que é justificado, devido ao fato de precisar mais recursos para competir em patamares estratégicos globais e uma curva de aprendizagem mais sofisticada, uma cultura corporativa mais globalizada, competências logísticas mais eficientes, áreas de produto e marketing mais integradas, maior expertise na gestão de facilidades e uma gestão financeira, contábil e tributária mais adaptável e flexível. Porém, não se pode generalizar para o conjunto das EMNs Brasileiras a predominância desta estratégia, pois, tratase do primeiro Caso Piloto, cujos demais casos poderão ou não confirmar a predominância desta estratégia.

Algumas filiais atuam na modalidade strategic asset seeking, e geralmente o fazem por meio da formação de parcerias e alianças estratégicas com empresas locais no ocidente europeu e nos EUA. A operação em países limítrofes e ou mais distantes dentro do continente é operacionalizada em muitos casos pela compra de outras empresas dos países receptores e representam um importante acesso a ativos estratégicos (Chudnovsky, 2004; Yeung \& Chung, 1999). Todavia, recentemente observa-se a por parte das empresas multinacionais brasileiras o processo de compra de concorrentes e parceiros no ocidente europeu e EUA, o que denota um ponto de inflexão e a ascensão da estratégia strategic asset seeking sobre a estratégia efficiency seeking e marketing seeking.

Sob a ótica da teoria das dimensões culturais de Hofstede (2011) a empresa possui a prevalência da aversão às incertezas como principal driver cultural, sendo forte a influência do fator masculinidade sobre o fator feminilidade. $O$ fator distância do poder é bastante discreto e os índices de participação dos empregados no poder decisório têm crescido substancialmente, principalmente em função do projeto de implantação lean -ou sistema de manufatura enxuta em curso. $\mathrm{Na}$ realidade o fator individualismo/coletivismo é determinante no processo decisório e tem um efeito suavizador sobre uma suposta concentração do poder pelo fator distância do poder. Na verdade, isto evidencia uma lacuna no modelo das dimensões culturais de Hofstede (2011), a dimensão individualismo/coletivismo é claramente preponderante para o individualismo nas empresas brasileira e neutraliza a preponderância do fator distância do poder.

Podemos concluir também que o caráter atual da competição possibilitou a estas empresas estruturas tecno-produtivas muito mais eficientes, embora muitas delas ainda operem com base na estratégia resource seeking ou marketing seeking. Alguns autores concluem que algumas empresas quanto se enquadram em uma fronteira estratégica marketing seeking e efficiency seeking, moldadas pelas próprias condições da competição atual entre as EMNS globais que impelem as empresas a incorporação de estratégias mais avançadas ou a ameaça bem concreta de serem adquiridas. (Garrido, 1999; Dunning, 1998).

\subsection{Discussão}

As empresas multinacionais brasileiras atuam em geral em setores commoditizados (têxteis, siderurgia, alumínio, papel e celulose, cimento, petroquímica, cerveja, alimentos) e isto têm implicações diretamente associadas aos seus resultados e a posse de ativos estratégicos. Mesmo não havendo políticas públicas explicitamente articuladas para suportam as necessidades de desenvolvimento destas empresas não se podem desprezar o apoio tácito dos governos locais e principalmente dos estados de origem (São Paulo, Rio de Janeiro, Santa Catarina, Minas Gerais, Rio Grande do Sul, Bahia e Espírito Santo).

$\mathrm{O}$ acesso às fontes de financiamento mais acessíveis do mercado internacionais (mercado bursátil) faz com que estas empresas alavanquem suas possibilidades de horizontalização e com o aval dos investidores internacionais que colocam recursos nestas empresas. É possível também concluir que tecnologicamente estas empresas tenham mais espaço em termos de incorporar novas tecnologias por meio de parcerias e joint ventures, as quais não conseguiriam em seus mercados locais de forma isolada. Podemos também afirmar que há espaço para a atuação em termos de estratégia strategic asset seeking nas áreas de software (joint ventures entre empresas brasileiras, americanas, taiwanesas e indianas) e biotecnologia 
Estratégias de Internacionalização de Empresas Multinacionais Brasileiras e Avaliação das Dimensões Culturais Nacionais: Estudo de Caso Setor de Fabricação de Implementos Agrícolas.

(EMNS americanas, Mexicanas e Brasileiras) e construção aeronáutica (Embraer, Airbus).

Receber os IDES é o ponto de partida para o desenvolvimento econômico, incremento da formação bruta de capital e estabilidade macroeconômica. Fortes ingressos de IDE geralmente são precedidos de emissões graduais, porém consistentes e com altas taxas de crescimento ao longo do tempo (Taiwan, Coréia do Sul, Singapura, Hong Kong). Todavia, todos estes "caminhos de desenvolvimento dos investimentos" parafraseando Dunning (1998) devem ser precedidos de uma agenda que considere estrategicamente a articulação das seguintes políticas articuladas essenciais à promoção dos IDE de multinacionais brasileiras: (i) Política Cambial: Deverá se promover uma política cambial flexível que não vincule problemas conjunturais e flutuações sazonais aos objetivos estratégicos de ganhos de competitividade de longo prazo; (ii) Política Tributária alinhada ao sistema tributário internacional: Acordos estáveis que evitem a dupla tributação são ideais para que haja incentivos para às atividades exportadoras de produção forânea de EMNS brasileiras que sejam semelhantes aos fatores de equilíbrio do regime automotivo; (iii) Políticas de Estímulo Planejado à Competitividade das EMNs Brasileiras: Estímulo à competitividade por meio de da maior divulgação das potencialidades do país, para incrementar a saída de IDE pela entrada de IDE e obtenção de saldos líquidos positivos, buscando-se compatibilizar as necessidades de curto prazo do balanço de pagamentos de forma a não prejudicar a importação de bens de capital e a saída de IDE; (iv) Política Industrial Articulada: Centralizar todas as portarias, regras, normas, regulamentos, consubstanciar em pacotes articulados e integrados que visem promover e descomplicar a atividade das EMNs brasileiras; (v) Política Tecnológica e de Inovação: Que possibilite o alcance de tecnologias inovativas e diferenciadas que possam conduzir as EMNS brasileiras aos níveis estratégicos superiores do Modelo de Dunning; efficiency seeking e strategic asset seeking.

\subsection{Limitações e Estudos Futuros}

As Limitações deste trabalho estão associadas ao fato de se tratar de um Caso Piloto e Único, para o qual não se pode extrair conclusões acerca da predominância estratégica, que explica a situação particular da empresa objeto do estudo de caso, porém, não permite generalizações, por estar na dependência de outros Casos Pilotos para a confirmação e ou desconfirmação de seus pressupostos.

\section{REFERÊNCIAS}

Aggarwal, R.; Ghauri, P. N. The evolution of multinationals from a small economy: a study of Swedish firms in Asia. In BUCKLEY, J. P.; CLEGG, J. (Org.) Multinational Enterprises in Less Developed Countries, London: Macmillan, 1993.

Bartlett, S. Christopher A.; Sumantra, G. Managing across borders: the transnational solution. London: Century Business, 1989.

Chudnovsky, D.; López, A. La inversión directa extranjera en la Argentina en los años 1990: tendencias, determinantes y modalidades. In Ministerio de Relaciones Exteriores, Comercio Internacional y Culto, Argentina de Cara al Mundo III. Buenos Aires, 1998.

Clark, I. Rehabilitation of mining sites. In Environmental policies, regulations and management practices in mineral resources development in Asia and the Pacific. United Nations, 1997.

Chudnovsky, D. A.; López; M. Freylejer, V. Environmental management in argentine industry: the diffusion of pollution prevention measures. In Technological innovation and sustainable development: case studies in the argentine manufacturing sector (Final Report of the Project on Competitiveness). Miami: IDRC/North South Center of the University of Miami Foundation, 1997.

Chudnovsky, D. A. Working Group on Development and Environment in Americas. Discussion paper number 3. Trade, Environment and Development: The Recent Argentine Experience. The Working Group on Development and Environment in the Americas, founded in 2004, brings together economic researchers from several countries in the Americas who have carried out empirical studies of the social and environmental impacts of economic liberalization. The Working Group's goal is to contribute empirical research and policy analysis to the ongoing policy debates on national economic development strategies and international trade. The Working Group held its inaugural meeting in Brasilia, March 29-30, 2004. This paper is one of eight written for the Brasilia meetings. They are the basis for "Globalization and the Environment: Lessons from the Americas," a policy report published by the Heinrich Böll Foundation in July 2004. The Policy Report and Discussion Papers produced by the Working Group can be found on the Web at: http://ase.tufts.edu/gdae/WorkingGroup.htm 
Estratégias de Internacionalização de Empresas Multinacionais Brasileiras e Avaliação das Dimensões Culturais Nacionais: Estudo de Caso Setor de Fabricação de Implementos Agrícolas.

Cooper, D. R.; Schindler, P. S. Métodos de pesquisa em administração. Porto Alegre: Bookman, 2003.

Dunning, J.H. Multinationals largest enterprises and the global economy. Addison-Wesley, 1993.

Dunning, J.H. Re-evaluating the benefits of foreign direct investment. Transnational Corporations, v. 3, no. $1,1994$.

Dunning, J.H; Van Hoesel, R; Narula, R. Third world multinationals revisited - new developments and theoretical implications. Working Papers no. 227, International Investment and Management, University of Reading, 1997.

Dunning, J. H. Location and the multinational enterprise: a neglected factor. Journal of International Business Studies, v. 29, no. 1, 1st quarter, 1998, pp. 45-66.

Eisenhardt, K. M. Building theories from case study research. Academy of Management Review, V. 14, No. 4. (Oct. 1989), pp. 532-550.

Eisenhardt, K. M.; Graebner, M. E. Theory building from cases: opportunities and challenges. Academy of Management Journal, 2007, v. 50, no. 1, p. 2532.

Ghemawat, P.; Reiche, S. The globalization note series. New York: IESE, 2011.

Ghemawat, P. The quasi-integration of markets, location-specificity and international business strategy. University of Harvard, 2002, (Mimeo).

Hemais, C.; Hilal, A. O processo de internacionalização na ótica da escola nórdica: evidências empíricas em empresas brasileiras. Revista de Ciências da Administração - RAC, v. 7, n. 1, Jan/Mar. 2003: 109-124.

Hofstede, G. National cultures, organizational cultures, and the role of management”. In González, F. (Org.), Values and Ethics for the $21^{\text {st }}$ Century. Madrid: BBVA, 2011, 459-81.

Hymer, S. H. In Cohen ET AL (eds), The Multinational Corporation, Cambridge: Cambridge University Press, 1979.

Johanson, J. E; Vahlne, J. E. The Uppsala internationalization process model revisited from liability of foreignness to liability of outsider ship. Journal of International Business Studies, 2009, v. 40, p. 1411-1431.
Kindleberger, C. P.; Hymer, S. The multinational corporation and contributions to political economy, 21, C Pitelis and R Sugden (Guest Eds).London, 2002.

Lall S. East Asia. In Dunning, J. (Org), Governments, Globalization and International Business. Oxford: Oxford University Press, 1997.MARSH, B. Environmental Policies, Regulations and Management Practices. In Mineral Resources Development in Asia and the Pacific, v. 2, 1997.

Michalet, C. A. Qu'est-ce que la mondialisation: petit traite a l'usage de ceux et celles qui ne savent pas encore s'il faut être pour ou contre. Découvert Edition, Paris: 2002.

Minkov, M., \& Hofstede, G. Hofstede's fifth dimension: New evidence from the World Values Survey. Journal of Cross-Cultural Psychology, 43(1), 3-14. (2012b).

Narula, R. The role of developing country multinationals in the acquisition of industrial technology in Nigeria. Science, Technology and Development. 1997, v. 15, No. 1.

O’Connor, D.; Turnham, D. Managing the environment in developing countries. OECD Development Centre, Policy Brief, 1993, n. 2

OECD - Organization For Economic Co-Operation And Development. Technology and the Economy: The Key Relationships. Paris: OECD, 1992.

OECD - Organization For Economic Co-Operation And Development. Foreign direct investment and the environment: an overview of the literature, 1998.

Oman, C. Policy Competition and Foreign Direct Investment, OECD Development Centre, Paris, 1998.

South Centre. Foreign direct investment, development and the new global economic order. A policy brief for the south, Geneva, 1997.

UNCTAD - United Nations Conference On Trade And Development. Fostering technological dynamism: evolution of thought on technological development processes and competitiveness: a review of the literature. Geneva: UNCTAD, 1996.

UNCTAD - United Nations Conference On Trade And Development. World Investment Report 1997: Transnational Corporations, Market, 1997a. 
Estratégias de Internacionalização de Empresas Multinacionais Brasileiras e Avaliação das Dimensões Culturais Nacionais: Estudo de Caso Setor de Fabricação de Implementos Agrícolas.

UNCTAD - United Nations Conference On Trade And Development. Management of commodity resources in the context of sustainable, $1997 \mathrm{~b}$.

Vernon, R. International investment and international trade in the product Cycle, Quarterly Journal of Economics, 1966, May, v. 80, n. 2.

Yeung, H.; Chung, W. The political economy of Singaporean investments in China. In East Asia Institute, Working Paper EAI, 1999, n. 22, National University of Singapore, Singapore, 1999.
Yeung, H.; Chung, W. Rethinking relational economic In East Asia Institute, Working Paper EAI, 2005, n11, National University of Singapore, Singapore, 2005.

Yin, R. K. Estudo de caso - planejamento e métodos. Porto Alegre: Bookman, 2005.

Wells, J. D.; Gobeli, D. H. The 3R framework: improving e-strategy across reach, richness, and range. Business Horizons (March-April 2003). 